Background The UK has higher rates of epilepsy deaths among children and young people than comparable countries, and poor care quality is a contributing factor a significant proportion of epilepsy-related deaths. Admission rates are widely used as a proxy measure of care quality in other paediatric conditions. For epilepsy, admission rates vary 4-5 fold between areas in England and the national clinical audit of paediatric epilepsy care (Epilepsy 12) shows wide variation in measures of care quality. It is not known whether better audit performance is associated with lower admission rates.

Objective To investigate the degree to which better performance in the national clinical audit is associated with lower admission rates for children and young people (0-19 years) with epilepsy.

Methods Independent variables: 12 unit-level quality indicators including access to paediatric, specialist nurse and paediatric neurologist expertise.(Round 1=2009-12; Round 2=2014) $\mathrm{n}=144$ units.

Dependent variable: unit-level epilepsy admission rate (admissions calculated from Hospital Episode Statistics (HES 2011/ 12-2013/14); estimated unit catchment populations derived from age-specific, all-cause admissions and population data).

Analyses

- Cross-sectional, multi-level regression models of Round 2 audit data and contemporaneous admission rates.

- Difference-in-difference analyses comparing time trends in performance measures and admission rates between 2011/12 and 2013/14.

All analyses excluded tertiary centres.

Results In 2013/14, matched data were available on 8685 epilepsy-related admissions across 144 units.

In the longitudinal model, increased involvement of paediatric neurologists was associated with a small relative increase in admission rates over time $(\beta=0.13$ (95\% CI: 0.03 to 0.22$)$, $\mathrm{p}=0.007)$. There was no significant relationship between paediatric neurologist involvement and admission rates in the cross-sectional model $(\beta=-0.04(-0.14-0.05))$. No other perfomance indicator from the Epilepsy12 audit was associated with adjusted, unit-level admission rates on either cross-sectional or longitudinal models.

Conclusions Neither cross-sectional nor longitudinal models showed any consistent relationship between performance on the national clinical audit and unit-level admission rates for epilepsy among children and young people. This may reflect inconsistency in how the performance indicators are interpreted and measured, as well as the limitations of admission rates as a proxy for good seizure and quality of life among children and young people with epilepsy.

\section{G306 TRANSITIONAL CARE FROM PAEDIATRIC TO ADULT FOR ADOLESCENT WITH EPILEPSY: LOCAL SURVEY}

Y Teh, C Kallappa, M Awadh, M Khan. Paediatric, Heart of England, Birmingham, UK

10.1136/archdischild-2018-rcpch.298

Background Transition is a 'planned, purposeful movement of the young person from a child centred to an adult orientated healthcare system'. ${ }^{1}$ The transitional period from paediatric to adult care can be challenging for adolescence with epilepsy. Children with chronic illnesses often struggle more than their peers during adolescence, when healthcare providers change from the nurturing, family-centred style of paediatrics to the individualistic, 'autonomous' approach of adult healthcare. ${ }^{2}$ Poorly managed transitional period can therefore cause poor treatment compliance, and may have long term implications on the epileptic control and well-being of the adolescence. ${ }^{3}$ According to the National Institute for Health and Clinical Excellence (NICE), adolescence with epilepsy should have an agreed transition care period with joint adult and paediatric services. ${ }^{4}$ Hence, this qualitative survey aims to understand the patients' perspective of the joint transitional clinic.

Methods A 7 questions, qualitative questionnaire is used to survey the transitional of care for adolescence with epilepsy in joint adult and paediatric service in our trust. The clinic is held 4 times a year, and attended to $35-40$ patients with the presence of paediatrician and adult neurologist. The questionnaire was distributed to the adolescent/parents during the transitional clinic.

Results The survey showed that $90 \%$ of patients are satisfied with the care, with $60 \%$ of respondents suggested that more information on the cause of epilepsy and possible side effects of medication should be provided. The survey also highlighted the issues of lengthy clinic waiting times and the need for several clinic visits before transfer. Additionally, parental/patients' concerns around driving, career options, contraception, and epilepsy inheritance were also raised.

Conclusion There are no data available to which model would best fit the transitional epilepsy clinic. However, the survey found that patients/parents are generally satisfied with the transitional care of joint paediatric and adult services. The transition process is complex. Therefore, the utilisation of best available resources such as, epilepsy nurses, family support groups, specific interest groups, and primary care services should be planned early. Lastly, future survey should address the concerns on education about driving, career options, epilepsy inheritance and contraception in adolescence with epilepsy.

\section{REFERENCES}

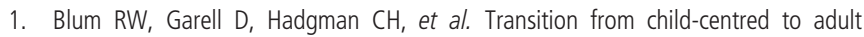
health-care systems for adolescents with chronic conditions: A position paper of the society for adolescent medicine. J Adol Health 1993;14:570-6.

2. Camfield P, Camfield C, Pohlmann-Eden B. Transition from paediatric to adult epilepsy care: A difficult process marked by medical and social crisis. Epilepsy Curr 2012 July-August; 12(Suppl 3):13-21.

3. Camfield P, Gibson P, Douglass L. Strategies for transitioning to adult care for youth with Lennox-Gastaut syndrome and related disorders. Epilepsia 2011;52 (Suppl 5):21-27.

4. National Institute of Clinical Excellence (NICE). Epilepsies: The diagnosis and management of the epilepsies in adults and children in primary and secondary care Clinical Guideline February 2016;137. NICE.

\section{G307(P) NATIONAL TRAINEES SERVICE EVALUATION OF THE MANAGEMENT OF IDIOPATHIC INTRACRANIAL HYPERTENSION (IIH) - PSEUDOTUMOR CEREBRI IN CHILDREN}

${ }^{1} \mathrm{~A}$ Amin, ${ }^{2} \mathrm{R}$ Spaull, ${ }^{1} \mathrm{R}$ Rattihalli, ${ }^{3} \mathrm{M}$ Atherton, ${ }^{4} \mathrm{~V}$ Mundada, ${ }^{5} \mathrm{E}$ Pilley, ${ }^{6} \mathrm{M}$ Moran, 'L Markham. 'University Hospitals Bristol, Bristol, UK; ${ }^{2}$ Gloucester Hospital, Gloucester, UK; ${ }^{3}$ Doncaster Hospital, Doncaster, UK; ${ }^{4}$ Royal London Hospital, London, UK; ${ }^{5}$ Edinburgh Hospital, Edinburgh, UK; ${ }^{6}$ Nottingham Hospital, Nottingham, UK

\subsection{6/archdischild-2018-rcpch.299}

Introduction IIH is characterised by raised intracranial pressure mostly affecting young females. It can lead to severe and irreversible visual loss. There is little consensus or evidence based 
guidance for management, especially in children. We conducted a multi-centre retrospective service evaluation to better understand current practice.

Methods Children diagnosed with IIH from nine centres in the UK over a 3 year period were retrospectively studied. Patient demographics, clinical details at presentation and follow-up, comorbidities, investigations, and medications were recorded and analysed.

Results 105 patients (71 females) with IIH, median age 11 [IQR 5-13] were recruited. Overall, record keeping was suboptimal with no recorded weight in 33\% (43/105), height in $64 \%$ (68/105); and visual acuity in 24\% (26/105).

At presentation $42 / 62 \quad(67 \%)$ of the patients had weight $>90$ th centile, behavioural issues were reported in 15/ $63(23 \%)$ and missing school in 9/43 (20\%). Papilloedema was reported in $98 / 105(93 \%)$ at baseline and in $87 / 105$ $(82 \%)$ at 6 months. Median GA opening CSF pressure was 34 (IQR 28 to 40) $\mathrm{cm} \mathrm{H} 2 \mathrm{O}$ and non-GA was 32 (IQR 25 to 39). $1 / 105(0.9 \%)$ had ICP monitoring and $1 / 105(1 \%)$ had shunt.

$73(69 \%)$ were seen by an ophthalmologist and 48 (45\%) had no record of either orbital US scan or OCT. Only $16(15 \%)$ had MRV and/or MRA. 51 (48\%) had LP under GA, of whom only 10 (19.6\%) had CO2 monitoring recorded. 92/ 105 (87\%) received acetazolamide, however 25/92 (27\%) had no electrolytes checked during acetazolamide therapy.

Conclusions This project highlights significant variation in the way that IIH is being investigated and managed in the UK. This variation is likely to reflect the paucity of evidence, but risks over-diagnosis and inappropriate management. These results should be used to form the basis for a national consensus for the diagnosis and management of IIH in young people.

\section{G308(P) SUDDEN UNEXPECTED DEATH IN EPILEPSY (SUDEP) DURING SLEEP IN THREE 17-YEAR-OLD ADOLESCENTS WITHOUT INTELLECTUAL DISABILITY}

${ }^{1}$ A Lim, 'V Ramesh, ${ }^{2} \mathrm{~S}$ Annavarapu, ${ }^{2} \mathrm{~T}$ Polvikoski. ${ }^{1}$ Paediatric Neurology, Newcastle NHS FT, Newcastle upon Tyne, UK; ${ }^{2}$ Pathology, Newcastle NHS FT, Newcastle upon Tyne, UK

\subsection{6/archdischild-2018-rcpch.300}

Aim To report risk factor(s) that might have led to SUDEP in three similar cases.

Methods Case note reviews; post-mortem reports; interviews with bereaved guardians/parents.

Results 17-year-old male had juvenile-onset generalised epilepsy diagnosed with onset at age 15. His generalised tonic-clonic seizures (GTCS) were mainly nocturnal; controlled with Valproate and Leveteracetam. His father saw playing on his computer at $1030 \mathrm{pm}$ and was found dead in his bedroom floor in early morning. No structural brain lesion demonstrated on postmortem except incidental right temporal pole arachnoid cyst. 17-year-old male with generalised epilepsy epilepsy with febrile seizures (GEFS+) with onset at age 2. His GTCS were relatively infrequent and only during intercurrent illness and had been treated with Valproate. He had been playing videogames throughout the night and went to bed the following evening. He was found dead at $930 \mathrm{pm}$ face down in his bed. 17-year-old female had presented with first episode of GTCS secondary to previously undiagnosed autoimmune hypothyroidism at age 15. Her Hashimoto encephalopahty was treated with steroids and thyroxine. After the initial presentation, no GTCS were reported. She was on thyroxine with no anti-epileptics. She had headache the day before. She was found dead face down in her bed in the early morning.

Discussion SUDEP typically affects 1 in 4500 children. Risk factors for SUDEP are young age, male sex, early onset, GTCS, and being in bed. Sodium channel mutation epilepsies are an at risk group for SUDEP. In this review, all three patients were aged 17 years and manifested only GTCS of varying aetiology. They had no intellectual disability or known poor compliance. All had been asleep in bed prior to SUDEP. Conclusions All three adolescents were sleep-related SUDEP. Potential strategies for prevention include avoiding sleep deprivation, counselling adolescents with sodium channel epilepsies and considering nocturnal seizure detection device.

\section{G309(P) PREDICTIVE VALUE OF ELECTROENCEPHALOGRAPHY FOR DEVELOPMENTAL OUTCOME AT 6 MONTH OF AGE IN FULL TERM NEONATES WITH SEIZURES}

M Ramwani, A Singh, I Shrivastava, A Agarwal. Department of Paediatrics, Gandhi Medical College, Bhopal, India

\subsection{6/archdischild-2018-rcpch.301}

Background Electroencephalography (EEG) is an important tool to evaluate infant with symptoms refer to central nervous system. The objective of the work was to study the predictive value of EEG for developmental outcome in full term neonates with seizures at 6 month of age.

Methods This was prospective observational study at tertiary care centre, Gandhi Medical College, Bhopal. The participants were full term hospitalised neonates with documented seizures. Newborns admitted for complaints other than seizures, hypoxic ischaemic encephalopathy (HIE) stage 1, preterm and neonates born to mother on antiepileptic therapy were excluded from the study.

Results Out of total 108 registered neonates 14 expired and 10 lost to follow up. In remaining 84 cases, 36 (42.9\%) had generalised discharge, 16 (19\%) had focal and $6(7.1 \%)$ had multifocal discharge while $44(52.3 \%)$ had normal EEG patterns. HIE being the most common cause and subtle seizure being the most common type of seizures. On follow up at 6 month, all neonates with normal EEG pattern $(n=44)$ had normal developmental outcome. Out of 40 neonates with abnormal EEG discharges, 26 (65\%) had developmental delay, while 14 (35\%) had normal development for age.

Conclusions EEG could be a simple and cost effective prognostic tool where neonates presenting with seizure. Newborn with abnormal discharge should be closely monitored on DDST for early identification and early intervention.

\section{G310(P) TACKLING EPILEPSY IN A DGH: SEIZING NICE QUALITY STANDARDS AND AUDITING AGAINST CURRENT PRACTICE}

S Ali, R Piggott, S Sastry, N Gulati. General Paediatrics, The Royal Wolverhampton NHS Trust, Wolverhampton, UK

\subsection{6/archdischild-2018-rcpch.302}

Objectives To compare our clinical practice against the NICE quality standards for children's epilepsy service. 